\title{
Thomas E. Brown, Quanjun Cui, William M. Mihalko, Khaled J. Saleh (eds): Expert consult arthritis and arthroplasty: the knee
}

\author{
Saunders Elsevier, Philadelphia, JUL-2009 + DVD, 189,91 $€$, Hardbound, \\ 352 pages, 400 ill., ISBN-13: 978-1-4160-4974*6
}

Pierre Kehr

Received: 16 August 2009 / Accepted: 18 August 2009 / Published online: 10 September 2009

(C) Springer-Verlag 2009

This work of more than 300 pages devoted to the surgery of the knee belongs to a new collection of five works entitled "Arthritis \& Arthroplasty". It gives a progress report on the state of the art in surgery of the knee which it is of the preserving techniques (arthroscopy, osteotomies, repair of the cartilage) or about the arthroplasty of first intention and revision. Various concepts such as conservation of the posterior cross ligament, postero-stabilization, mobile plate but also uni-compartimental arthroplasty or femoro-patellar arthroplasty.

An important chapter is devoted to the approaches and two others with ligamentous balance. The major part of the work is reserved for the revision with its specific problems: osseous stock, cutaneous problems, ablation of the implants, choice of the new implants, attitude with respect to the patella.

The last part of the work is devoted more particularly to management of the complications: perish-prosthetic infection, stiffness, fractures, rupture of the apparatus bungee cord. The articles generally synthetic, are richly illustrated with diagrams and color photographs making their reading attractive. The bibliography is not exhaustive but is sufficient and a suggestion of references selected by the author at the end of the chapter enable the reader to enhance his knowledge. Last, a certain number of video films are available on the DVD included in the work but also "online" supplementing the text usefully.

This work is addressed not only to the orthopeadic surgeon specialist in the knee but also to the surgeon in formation or those who wish to improve their knowledge of the surgeryof the knee.

No funds were received in support of this study.

Laurent Galois

P. Kehr $(\square)$

ArgoSpine, Strasbourg, France

e-mail: kehrpier@aol.com 